\title{
DESAIN DAN IMPLEMENTASI MODEL PEMBELAJARAN \\ E-LEARNING DI PROGRAM STUDI TEKNIK ELEKTRO \\ UNIVERSITAS 17 AGUSTUS 1945 CIREBON DENGAN \\ MODULAR OBJECT ORIENTED DYNAMIC LEARNING ENVIRONMENT
}

\author{
Vidya Ikawati \\ Program Studi Teknik Elektro \\ Fakultas Teknik UNTAG Cirebon \\ Email : ikawatividya@gmail.com
}

\begin{abstract}
ABSTRAKSI
Meningkatnya jumlah jaringan internet membuat dampak yang cukup berarti untuk bidang pendidikan. Dimana pada dasarnya pendidikan adalah proses komunikasi antara pendidik kepada peserta didik. Seiring dengan perkembangan zaman, jumlah kehadiran mahasiswa semakin sedikit dibandingkan dengan proses pendidikan berpuluh tahun yang lalu. Oleh karena itulah perlu dibuat alternatif media pembelajaran sebagai komplemen pembelajaran di kelas. Program Studi Teknik Elektro UNTAG Cirebon sebagai salah satu penyelenggara pendidikan di Indonesia berupaya mengatasi masalah ini dengan membuat media pembelajaran berupa elearning yang proses pembuatannya berbasiskan Moodle dan MySQL.
\end{abstract}

Keyword : e-learning, Moodle, MySQL

\begin{abstract}
The increasing number of Internet networks make a significant impact on education. Where education is essentially a process of communication between the educator to the learners. Along with the times, the number of student attendance is fewer than the number of student attandance decades ago. Therefore, it needs to be made of an alternative learning media to complement classroom learning. Electrical Engineering of UNTAG Cirebon as one of the organizers of education in Indonesia is trying to overcome this problem by creating a learning media in the form of e-learning that the manufacturing process is based on Moodle and MySQL.
\end{abstract}

Keyword : e-learning, Moodle, MySQL.

\section{PENDAHULUAN}

Munculnya penemuan internet pada tahun 1969 mengakibatkan perkembangan teknologi informasi bergerak dengan cepat, sehingga dengan perkembangan ini telah mengubah paradigma masyarakat dalam mencari dan mendapatkan informasi, yang tidak lagi terbatas pada informasi surat kabar, audio visual dan elektronik, tetapi juga sumber-sumber informasi lainnya yang salah satu diantaranya melalui jaringan Internet. Salah satu bidang yang mendapatkan dampak yang cukup berarti dengan perkembangan teknologi ini adalah bidang pendidikan, dimana pada dasarnya pendidikan merupakan suatu proses komunikasi dan informasi dari pendidik kepada peserta didik yang berisi informasiinformasi pendidikan, yang memiliki unsurunsur pendidik sebagai sumber informasi, media sebagai sarana penyajian ide, gagasan dan materi pendidikan serta peserta didik itu sendiri beberapa bagian unsur ini mendapatkan sentuhan media teknologi informasi, sehingga mencetuskan lahirnya ide tentang e-learning (Utomo, 2001).

Pembelajaran di kelas dalam satu semester memiliki jumlah pertemuan minimal 14 kali pertemuan. Namun pada kenyataannya, tidak sedikit mahasiswa yang tidak memenuhi jumlah pertemuan tersebut. Hal ini mengakibatkan terjadinya ketimpangan pengetahuan antar mahasiswa dalam satu kelas. Oleh karena itu, 
mahasiswa memerlukan sebuah media pembelajaran yang diakses bersama baik oleh dosen ataupun oleh seluruh mahasiswa yang terdaftar dalam perkuliahan dalam satu semester. Media pembelajaran tersebut adalah media elearning.

Oleh karena itu model pembelajaran elearning perlu diciptakan untuk memudahkan proses belajar mahasiswa dan proses mengajar dosen.

Definisi e-learning

Jaya Kumar C. Koran (2002), mendefinisikan e-learning sebagai sembarang pengajaran dan pembelajaran yang menggunakan rangkaian elektronik (LAN, WAN, atau internet) untuk menyampaikan isi pembelajaran, interaksi, atau bimbingan. Ada pula yang menafsirkan e-learning sebagai bentuk pendidikan jarak jauh yang dilakukan melalui media internet.

Kehadiran dosen di kelas untuk menerangkan materi, membentuk kelompok diskusi, memberikan tugas dan tes memang tidak akan pernah tergantikan denga alasan adanya pengawasan langsung dari dosen yang bersangkutan. Namun ada kalanya dosen tidak bisa hadir dan harus memberikan materi pembelajaran sesuai dengan Garis-Garis Besar Pembelajaran (Soekarwati,2000). Maka dibutuhkan sebuah media pendukung sebagai perantara antara dosen dan mahasiswa.

Fungsi dan Manfaat E-Learning

Ada 3 (tiga) fungsi pembelajaran elektronik terhadap kegiatan pembelajaran di dalam kelas (classroom instruction), yaitu sebagai suplemen yang sifatnya pilihan/opsional, pelengkap (komplemen), atau pengganti (substitusi)(Siahaan, 2002).

\section{a. Suplemen}

Dikatakan berfungsi sebagai supplemen (tambahan), apabila peserta didik mempunyai kebebasan memilih, apakah akan memanfaatkan materi pembelajaran elektronik atau tidak. Dalam hal ini, tidak ada kewajiban/keharusan bagi pesertadidik untuk mengakses materi pembelajaran elektronik. Sekalipun sifatnya opsional, peserta didik yang memanfaatkannya tentu akan memiliki tambahan pengetahuan atau wawasan.

\section{b. Komplemen (tambahan)}

Dikatakan berfungsi sebagai komplemen (pelengkap) apabila materi pembelajaran elektronik diprogramkan untuk melengkapi materi pembelajaran yang diterima siswa di dalam kelas (Soekartawi, 2003). Sebagai komplemen berarti materi pembelajaran elektronik diprogramkan untuk menjadi materi reinforcement (pengayaan) atau remedial bagi peserta didik di dalam mengikuti kegiatan pembelajaran konvensional. Materi pembelajaran elektronik dikatakan sebagai enrichment, apabila kepada peserta didik yang dapat dengan cepat menguasai/memahami materi pelajaran yang disampaikan guru secara tatap muka (fast learners) diberikan kesempatan untuk mengakses materi pembelajaran elektronik yang memang secara khusus dikembangkan untuk mereka(Syah, 2002).

\section{c. Substitusi (pengganti)}

Pada kondisi dimana terjadi program pendidikan jarak jauh, maka e-learning akan menjadi media subtitusi pembelajaran di kelas. Karena faktor jarak, maka dosen dan mahasiswa akan lebih mudah berkomunikasi melalui media internet dibandingkan bertatap muka langsung.

Teknologi Pendukung E-learning

Menurut Onno W. Purbo (1997), "ada lima aplikasi standar internet yang dapat digunakan untuk keperluan pendidikan, yaitu email, Mailing List (milis), News group, File Transfer Protocol (FTC), dan World Wide Web (WWW)".

Moda aplikasi email digunakan untuk komunikasi peer to peer. Sehingga seorang dosen hanya bisa berkomunikasi dengan seorang mahasiswa. Akhirnya, dosen hanya mewakilkan seorang mahasiswa untuk menyampaikan materi pembelajaran ataupun tugas kepada mahasiswa yang lain.

Moda aplikasi milis memperbolehkan banyak pengguna mengikuti diskusi sebuah grup dan memberikan keuntungan broadcast, namun milis memiliki kelemahan untuk 
diskusi secara terpusat dan sulit menyimpulkan diskusi.

News grup tidak berbeda dengan milis, namun memiliki kelebihan diskusi yang terpusat. Sedangkan File Transfer Protocol (FTP) memiliki kelemahan dengan tidak adanya forum diskusi. Dan yang terakhir adalah World Wide Web (WWW) merupakan teknologi yang paling canggih yang ditemukan akhir-akhir ini sebagai media untuk mendukung e-learning. Karena di dalamnya terdapat fitur email, milis, news grup, dan FTC.

\section{METODE PENELITIAN.}

2.1 Komponen-Komponen Dalam Framework Learning Management System

Dalam menyusun sebuah kerangkan berpikir (framework) dari sebuah perancangan/rekayasa perangkat lunak, maka hal pertama yang harus dilakukan adalah menganalisis komponen-komponen dalam organisasi yang akan terlibat dalam penggunaan software tersebut. Organisasi unversitas adalah organisasi pembelajar. Organisasi pembelajar yang fokus pada manusia dapat menerapkan LMS Framework yang memiliki komponen pemodelan sebagai berikut:

\section{A. Manusia}

Manusia sebagai subjek utama dalam Learning Management dapat berupa individu atau komunitas yang memiliki peran (role) tertentu. Dalam LMS framework, manusia difokuskan pada peran sentral sebagai inisiator terjadinya prosesproses knowledge management.

\section{B. Proses Pengetahuan}

Proses pengetahuan merupakan proses yang dilakukan terhadap pengetahuan.

\section{Artefak Pengetahuan}

Artefak pengetahuan adalah bentuk nyata / eksplisit hasil dari proses pengetahuan yang dapat dijadikan referensi untuk proses-proses pengetahuan selanjutnya.
D. Teknologi
Teknologi digunakan sebagai enabler dan supporting system untuk

memungkinkan terjadinya Knowledge Management yang efektif dan efisien. Teknologi yang paling baik adalah yang paling mudah digunakan oleh subjek (Manusia).

E. Lingkungan Pembelajaran

Lingkungan Pembelajaran dipahami sebagai lingkungan tempat diimplementasikannya Knowledge Management. Baik lingkungan fisik maupun lingkungan organisasional.

2.2 Interaksi Antar Komponen Dalam

Lingkungan Learning Management System

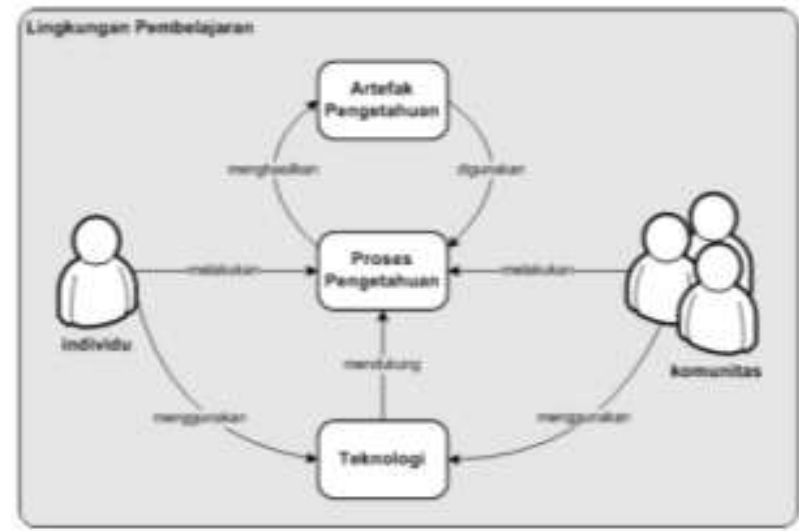

Gambar 1. Interaksi dalam lingkungan pembelajaran

Penjelasan interaksi antar komponen LMS adalah sebagai berikut :

1. Lingkungan pembelajaran sebagai komponen yang melingkupi komponenkomponen yang lain. Lingkungan pembelajaran mencakup lingkungan fisik/geografis dan lingkungan budaya organisasional.

2. Manusia (Individu dan Komunitas) saling berinteraksi dengan melakukan proses pengetahuan. Dalam hal ini, manusia yang terlibat memiliki perannya masing-masing.

3. Teknologi digunakan oleh Manusia untuk mendukung pelaksanaan proses pengetahuan agar lebih optimal.

4. Artefak pengetahuan dihasilkan melalui proses pengetahuan dan digunakan kembali dalam proses pengetahuan untuk menciptakan pengetahuanpengetahuan lainnya. 


\subsection{Work Flow Diagram}

Untuk menentukan hubungan antara dosen, mahasiswa dan admin dalam elearning ini, maka perlu dibuat Work Flow Diagram yang ditampilkan sebagai berikut.
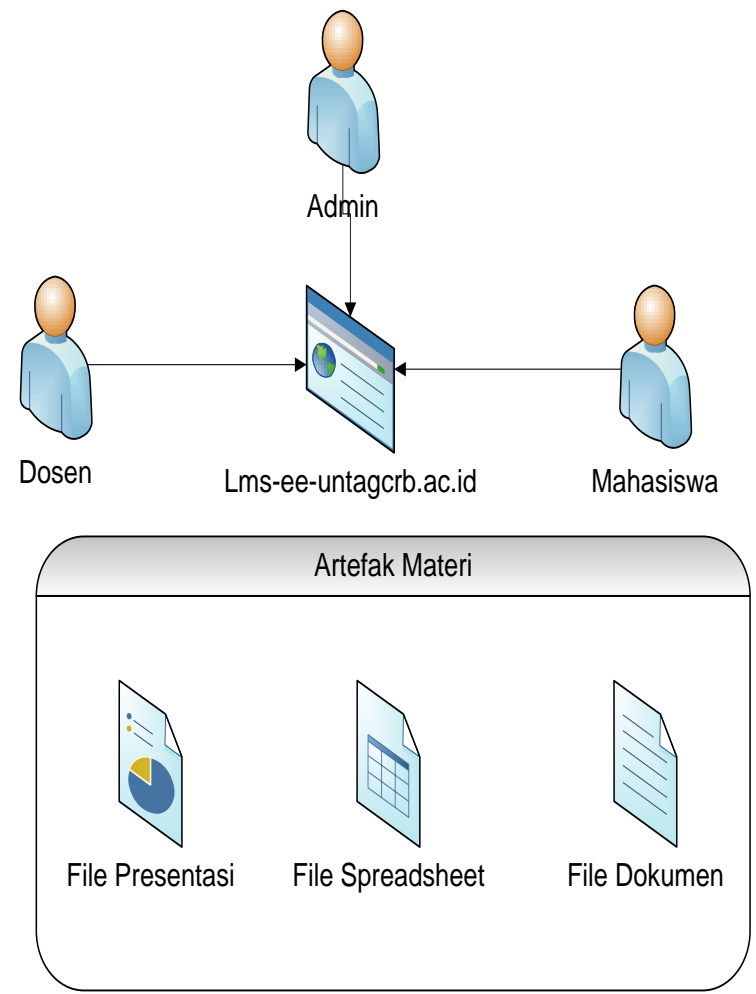

Gambar 2. Work Flow Diagram elearning : lms-ee-untagcrb.ac.id

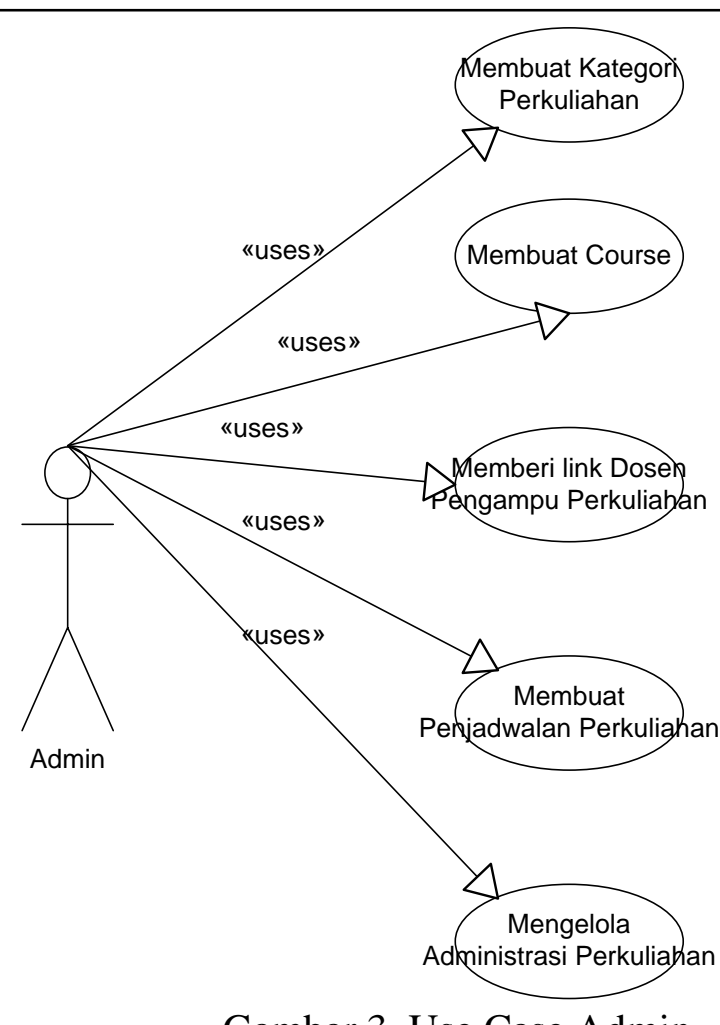

a. Diagram Dosen

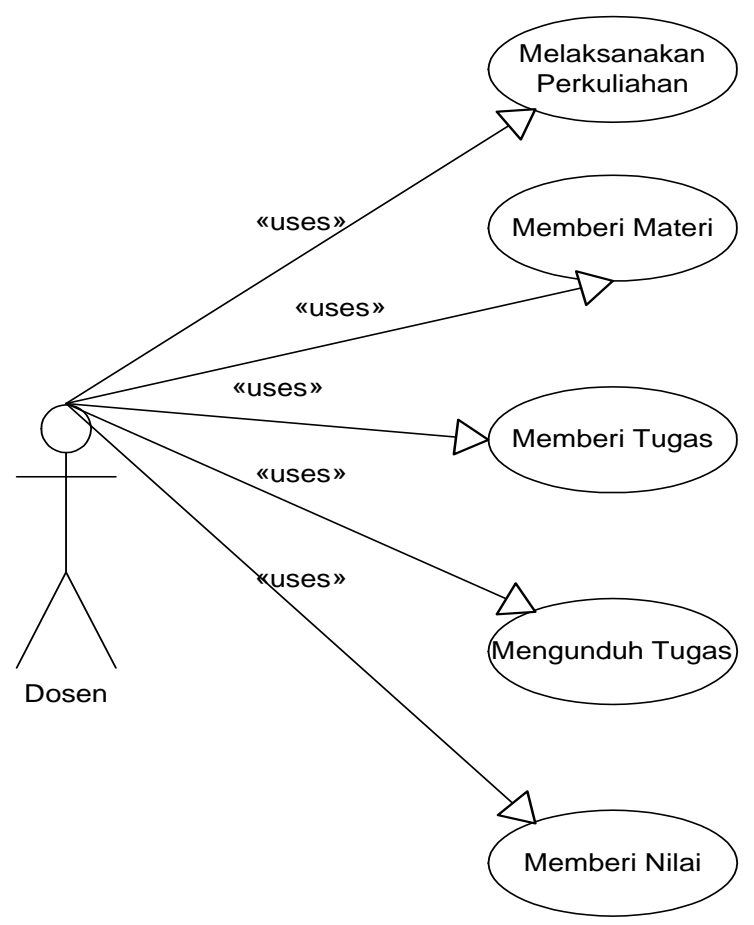

Gambar 4. Use Case Dosen

b. Diagram Mahasiswa 


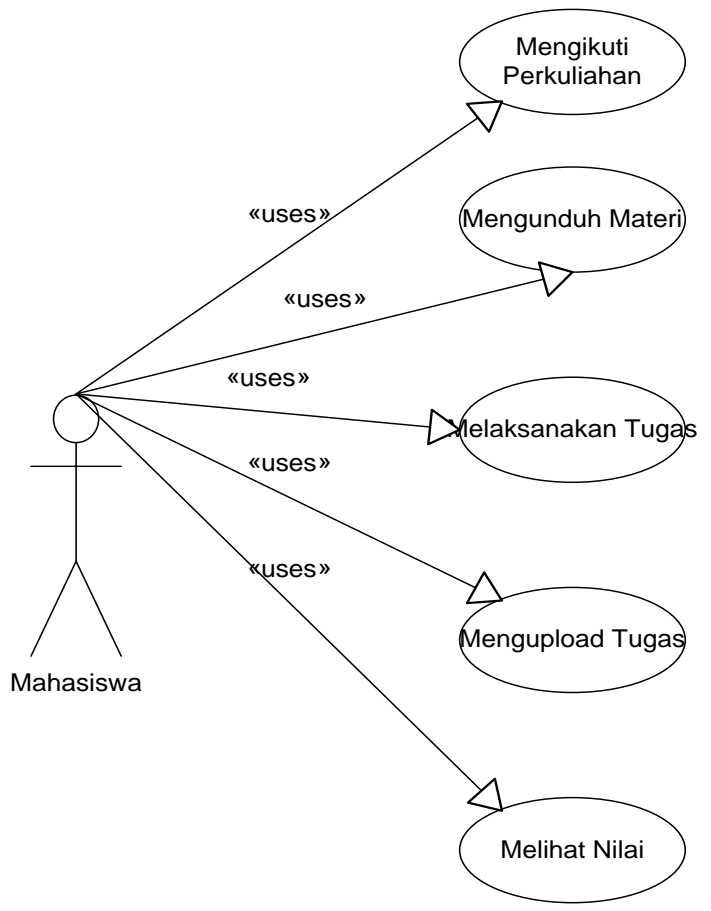

Gambar 5. Use Case Mahasiswa

2.4 Data Flow Diagram (DFD)

a. DFD Proses Login

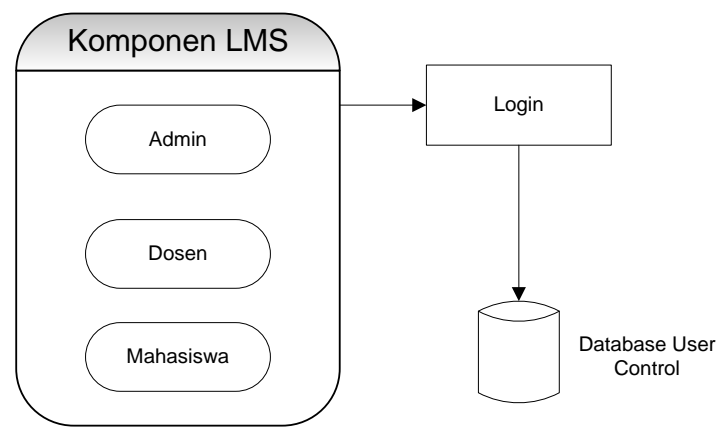

Gambar 6 DFD Proses Login

b. DFD Menu Utama

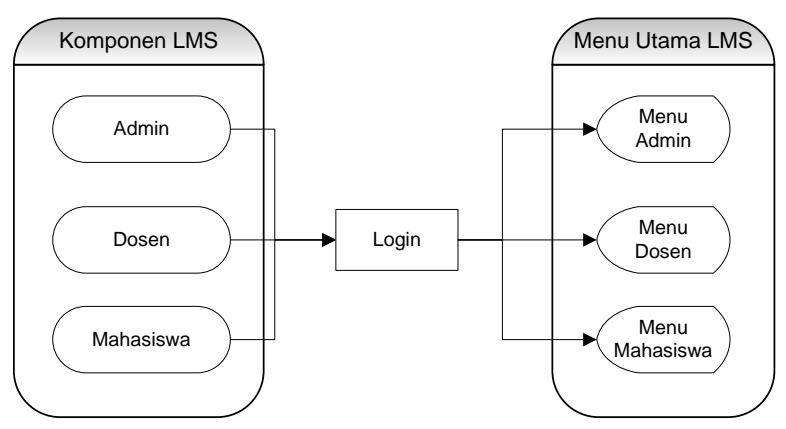

Gambar 7 DFD Proses Login c. DFD Course Category

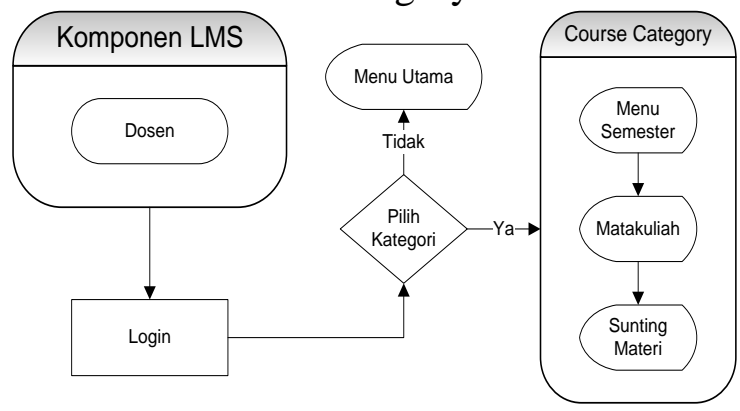

Gambar 8 DFD Course Category

d. DFD Course (Mata Kuliah)

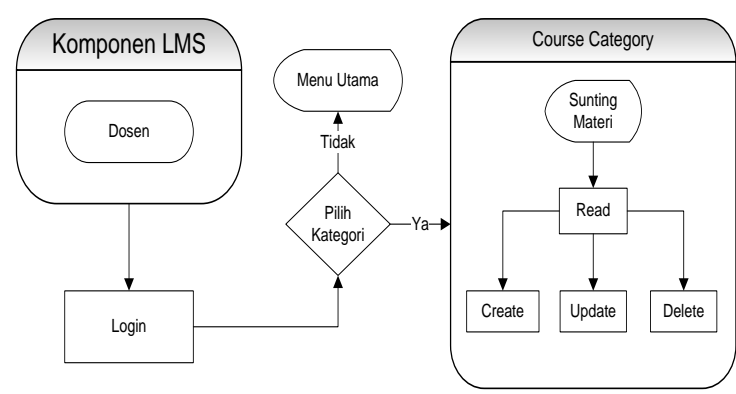

Gambar 9 DFD Mata Kuliah

e. DFD Outline Perkuliahan (Per pertemuan)

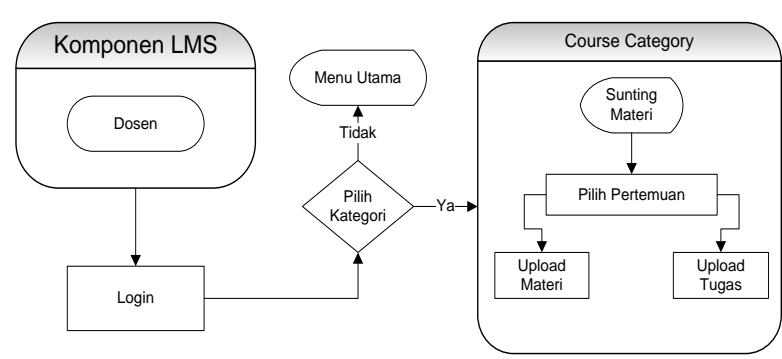

Gambar 10 DFD Outline Perkuliahan

f. DFD Mengerjakan Tugas

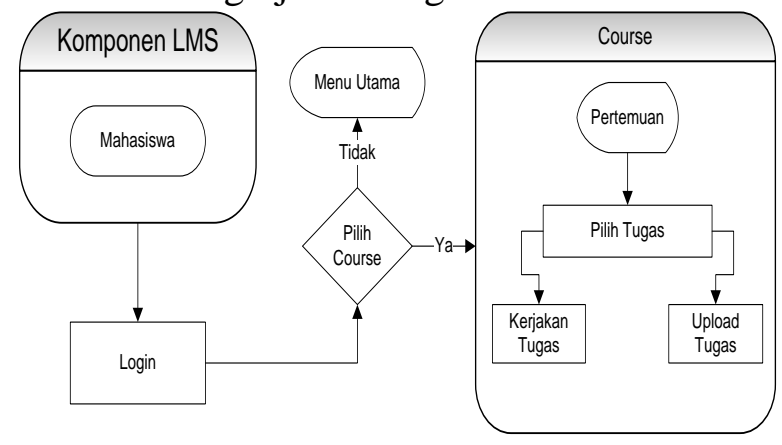

Gambar 11 DFD Mengerjakan Tugas

g. DFD Melihat Nilai 


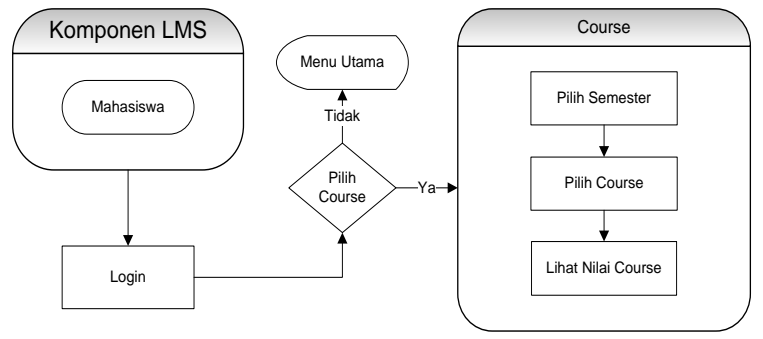

Gambar 12 DFD Melihat Nilai

h. DFD Melihat Profil User

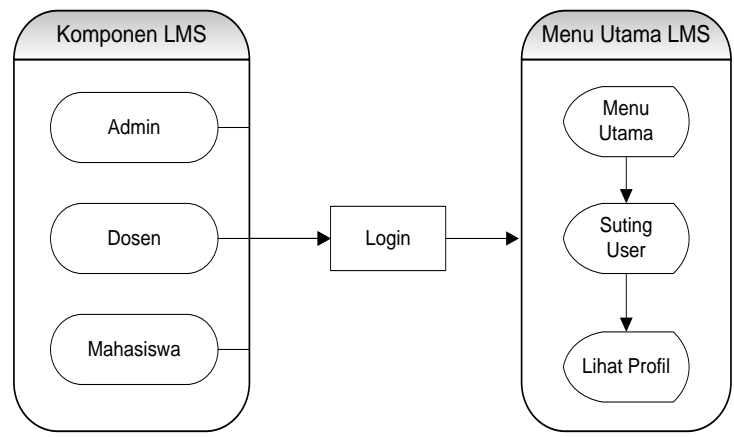

Gambar 13 DFD Melihat Profil

i. DFD Forum

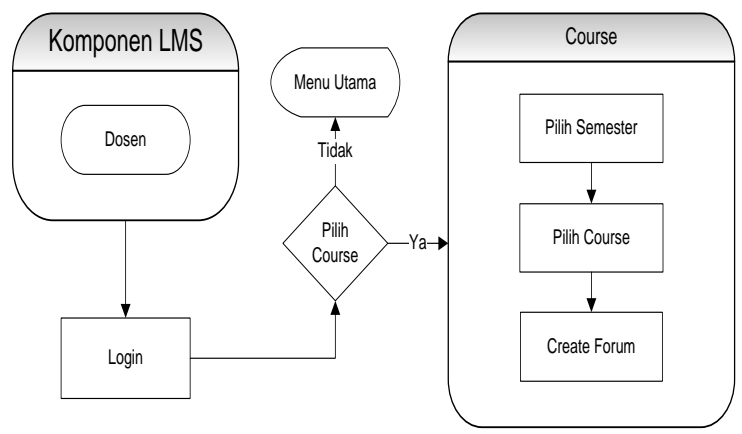

Gambar 14 DFD Menciptakan Forum.

\section{HASIL DAN ANALISA}

Pada penelitian ini, e-learning yang dibangun menggunakan Modular Object Oriented Dynamic Learning Environment (Moodle). Moodle merupakan sebuah aplikasi Course Management System (CMS) yang dengan lisensi secara GNU (General Public License). Moodle dikembangkan di lingkungan platform LAMP (Linux, Apache, MySQL, dan PHP) namun telah dites juga dengan data base PostgreSQL. Moodle juga pernah diuji pada lingkungan Windows XP dan Netware 6. Untuk menjalankan Moodle di Linux diperlukan:
1. Webserver Apache.

2. PHP versi 5.1.0 ke atas

3. Database server MySQL atau Potgre SQL. Versi Moodle selanjutnya juga akan mendukung software database lainnya.

1. Halaman login

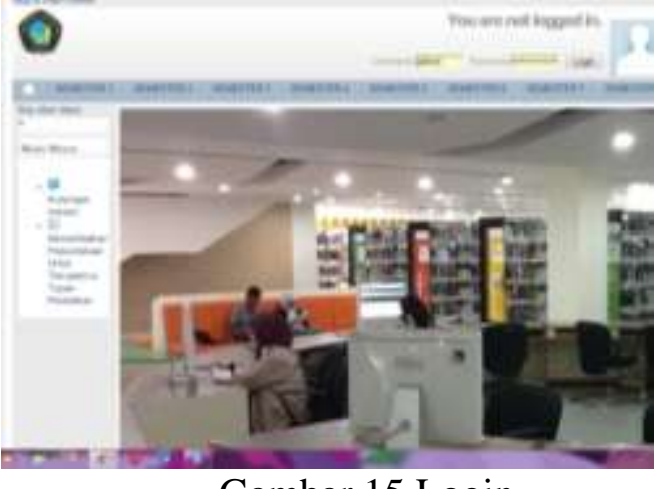

Gambar 15 Login

\section{Menu Utama}

Setelah login, maka halaman yang akan tampil adalah menu utama. Menu ini terhubung dengan seluruh course category. Course category dalam penelitian ini adalah masin-masing semester, dari semester 1 hingga semester 8 .

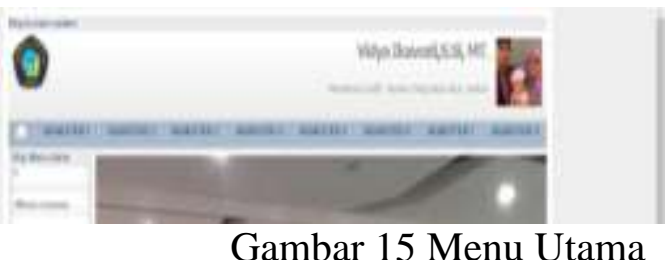

3. Halaman course category

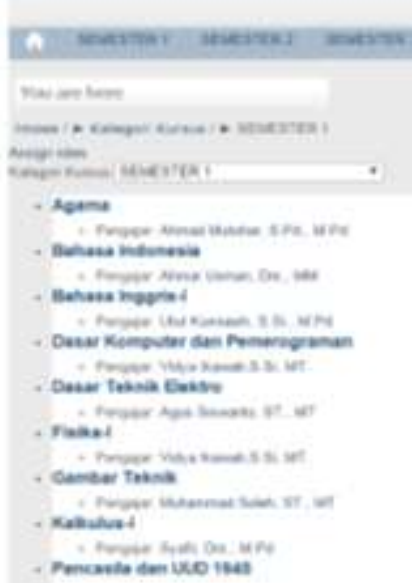

Gambar 16 Course Category

4. Halaman Weekly Outline 


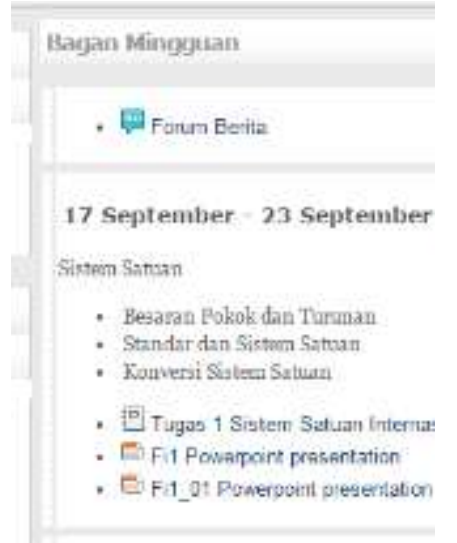

Gambar 17 Weekly Outline

5. Pengaturan administrasi

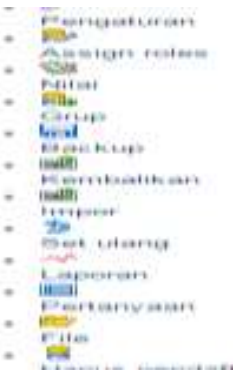

Gambar 17 Pengaturan Administrasi

6. Halaman tugas

Dosen dapat melihat keseluruhan tugas yang telah dibuatnya dan berapa orang yang telah mengerjakan tugas tersebut.

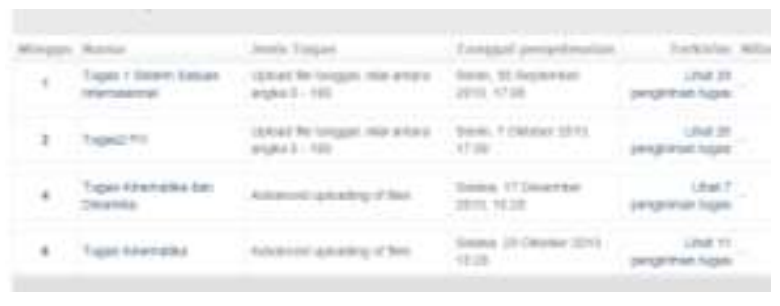

Gambar 18 Halaman Tugas

\section{KESIMPULAN}

Beberapa hal yang dapat dismpulkan dari perancangan dan implementasi elearning di Prodi Teknik Elektro Untag Cirebon ini adalah:

1. Dalam mendesain e-learning penelitian ini digunakan Framework Learning
Management System Moodle dengan analisa Interaksi antar Komponen Lingkungan Pembelajaran untuk menentukan kebutuhan-kebutuhan sistem.

2. Mengimplemetasikan learning management system ini, komponen yang terlibat tidak diletakkan dalam sebuah tempat yang dekat melainkan tempat mobile yang tidak hanya dapat dijangkau dengan hubungan antar komputer dalam jangkauan LAN. Oleh karena itu, sistem yang harus dibuat adalah sebuah sistem mobile yang dapat diakses komponenkomponen tersebut kapanpun dan dimanapun. Maka untuk dapat memenuhi kebutuhan tersebut, sistem harus dibuat dalam sebuah browser yang dapat dimiliki oleh siapapun tanpa harus memiliki sebuah perangkat API tambahan. Dengan adanya browser, maka HTML dijadikan implementasi dalam penelitian ini.

\section{DAFTAR PUSTAKA}

Koran, Jaya Kumar C. (2002), Aplikasi ELearning dalam Pengajaran dan pembelajaran di Sekolah Malaysia. (8 November 2002).

Syah, Muhibbin. (2002). Psikologi Pendidikan dengan Pendekatan Baru. Bandung : Rosda karya

Soekarwati., (2000), Prospek Pembelajaran Melalui Internet, Makalah Seminar Teknologi Kependidikan, UT Pustekkom dan IPTPI, Jakarta

Soekartawi, (2003) Prinsip Dasar ELearning: Teori Dan Aplikasinya Di Indonesia, Jurnal Teknodik, Edisi No.12/VII/Oktober/2003.

Utomo, Junaidi. (2001). Dampak Internet Terhadap Pendidikan : Transformasi atau Evolusi, Seminar Nasional Universitas Atma Jaya Yogyakarta. 